\title{
Claim Specialization, Tactical Diversity and the Role of the Protest Environment in the Success of U.S. Antinuclear Activism
}

\author{
Alessandro Piazza \\ Rice University \\ alessandro.piazza@rice.edu \\ Dan J. Wang \\ Columbia University \\ djw2104@,columbia.edu
}

Mobilization: An International Quarterly, 2020, 25(1): 93-114

\begin{abstract}
Why are some protests from a seemingly unified social movement more effective against similar organizational targets than others? In this article, we make the claim that protests are more likely to succeed when: (1) their claims are more specialized to their targets; and (2) when they draw on a more diverse repertoire of tactics. We also contend that the extent to which claim specialization facilitates protest success is a function of competition in the form of other geographically proximate protests advancing alternative claims. Finally, we argue that the effect of claim specialization on protest success is contingent on the features of the surrounding protest environment. A study of planned nuclear generating units in the U.S. and the antinuclear protest that targeted them between 1960 and 1995 provides support for our arguments, with implications for how the pace of social change can be linked to the intensity of cross-movement alliances.
\end{abstract}




\section{Introduction}

Throughout the 1950s and 1960s, several locations in coastal California became the backdrop to the genesis of the U.S. anti-nuclear energy movement. In 1958, Pacific Gas \& Electric (PG\&E) announced its intention to build the nation's first commercially viable nuclear power plant in Bodega Bay, just north of San Francisco. Just seven years later, PG\&E proposed the construction of another plant at Diablo Canyon, a few hundred miles down the California coast near San Luis Obispo. Local activists mobilized in both instances, fomenting an enduring movement that would span decades and countries (Rucht 1990). However, although anti-nuclear energy campaigns increasingly captured the attention of policy-makers and other stakeholders, not all protests against nuclear power plants in the U.S. were successful in halting the proliferation of nuclear energy.

Returning to our examples, protestors succeeded in defeating the proposal at Bodega Bay (Wellock 1998), but failed in stopping the construction of the Diablo Canyon plant, which came on line in 1985 (Wills 2006). On the surface, these two cases of anti-nuclear protest appear similar: the plants were proposed by the same company, in the same region, with similar stakes, and were challenged by similarly sized protests. What explains the difference in outcomes? Aside from historical context, we argue that past scholarship has underemphasized how certain features of the protest events themselves might also account for its success in preventing the spread of nuclear energy.

In this paper, we explore the extent to which the range of a protest's claims - defined as collective demands or grievances that support or oppose some change in society (Tilly 2004) — and tactics — or the activities through which claims are conveyed in public protest events (Tarrow 2011) - are related to movement outcomes. Specifically, we examine a large sample of anti-nuclear energy protest events to gain insight into how spanning different movement claims and tactical repertoires might be related to whether proposals for nearby nuclear power plants are halted (Heaney and Rojas 2014; Olzak and Ryo 2007; Wang and Soule 2016). A closer examination of our example above reveals that the successful 
protestors at Bodega Bay - mostly led by conservationists at the local chapter of the Sierra Clubarticulated a specialized set of claims, based on the narrow grounds that it would endanger the unique natural environment. By contrast, the unsuccessful protest activity against Diablo Canyon was much less focused, motivated by a broader set of goals (Wellock 1998). The involvement of social movement organizations (SMOs) such as the Abalone Alliance, representing the anti-corporate lobbying interests, and Mothers for Peace, an anti-Vietnam War group, ultimately blurred the intentions of the Diablo Canyon protests (Wills 2006).

The above comparison, although admittedly stylized, suggests that boundary-spanning — or the extent to which protests bridge different issues - might explain the variance in collective action outcomes (Wang, Piazza, and Soule 2018). In extant research, the question of whether specialization-vis-à-vis breadth - in tactics and claim-making enhances protest success has generated important theoretical perspectives, but has led to a mixed set of conclusions. For instance, Gamson (1975) suggests that protests specializing in fewer claims tend to be more effective at pressing for social change. Related, McVeigh, Myers, and Sikkink (2004) suggest that articulating claims that resonate with local concerns tend to make protests more effective. By contrast, more recent research by Heaney and Rojas (2014) advances the idea that hybridity in movement goals-rather than specialization-is crucial for mobilization.

A similar question, i.e., whether movement actors should opt for a diverse range of tactics as opposed to a limited repertoire, has also sparked a lively debate (Taylor and Van Dyke 2004). In a study of the peace, women's, and environmental movements, Soule and King (2008) found that tactically diverse SMOs are less likely to survive when a given social movement industry becomes more concentrated. Olzak and Ryo (2007), however, found tactical breadth to be beneficial in shaping policy outcomes in the environmental movement. In all, the question of whether tactical and goal specialization is helpful to movement success is all but settled (Giugni 1998). 
In this paper, we investigate how specialization in protest claims and tactics relates directly to the achievement of protest goals in a study of mobilization against nuclear reactor proposals in the United States. By analyzing anti-nuclear energy protests, we observe an outcome that unambiguously signals protest success - i.e., whether proposed nuclear reactors that are geographically proximate to anti-nuclear protest events are terminated at some point during their proposal, development, or construction. Furthermore, we shift the level of analysis to the protest event - rather than the SMO — to theorize about how protest-level features related to claim and tactical specialization might influence immediate movement outcomes.

Below, we develop a set of hypotheses about claim specialization and tactical diversity in antinuclear protests, building on research in organizational and economic sociology on boundary-spanning (Zuckerman 1999; Zuckerman et al. 2003). With respect to our empirical setting, we show that an antinuclear protest is more likely to be followed by the termination of a nuclear reactor project when the protest's claims are more specialized, and when the tactics deployed are more diverse. In what follows, we briefly review the literature on social movement outcomes, and we develop hypotheses about the relationship between claim specialization, tactical diversity, and protest success. We then present our data and empirical strategy, discuss our results, and elaborate on their implications for the literature on collective action outcomes.

\section{Past perspectives on specialization and movement outcomes}

Research on the relationship between movement specialization and movement success can generally be categorized based on (1) the different dimensions in which movement actors can specialize and (2) the different outcomes associated with such specialization. In terms of the types of movement specialization, scholars have examined claims - i.e., movement actors' grievances - and tactics - i.e., the strategies and tools of protest at a movement actor's disposal. On outcomes, past work has largely 
been concerned with either protest success - i.e., the extent to which activists have achieved their stated goals - or resource mobilization - i.e., the aggregation of money, labor, and organizational skill to “deliver collective goods” (McCarthy and Zald 1977: 1216).

Diversity and breadth in tactics and claims can generally advantage movement actors in pursuit of organizational resources. McCarthy and Zald (1977) argued that movements activate pathways for resource accumulation by achieving resonance with multiple audiences and constituencies, who might serve as providers of funding, participants, or other organizational resources. In their study of the antiwar movement after 9/11, Heaney and Rojas (2014) found that organizations with hybrid identities - i.e. organizations that span multiple constituencies and champion multiple claims for change-enjoy unique advantages in recruitment. Relatedly, breadth in claims also enables movement groups to obtain other types of resources, such as knowledge about how to deploy novel tactics and strategies. For example, Minkoff (2002) demonstrates that non-profit organizations that hybridize by "borrowing the language of other movements" tend to be nimbler in adapting new strategies in the face of significant external challenges. In more recent work, Wang and Soule (2016) find that protests making cross-movement claims are the crucibles of tactical innovation while Wang and Piazza (2016) show how protests representing more diverse claims are more likely to deploy more resource-intensive disruptive strategies. In addition, protest groups that make diverse claims and tactics also tend to engage in a greater volume of protest activity (Olzak and Ryo 2007), which suggests that adopting robust identities (Zuckerman et al. 2003) and a broad tactical playlist can sustain and grow support for a movement.

Although some consensus exists that greater diversity in claims and tactics is associated with more effective resource mobilization, the literature on whether this same diversity leads to greater protest success has generated mixed evidence. On the one hand, forging hybrid identities can galvanize new support for a waning movement, empowering activists against incumbents, such as the case of the labor movement in the 1960s (Isaac and Christiansen 2002; Isaac, McDonald, and Lukasik 2006). Channeling 
protest through diverse goals and tactics can also put additional pressure on targets by subjecting incumbents to challenges from different audiences and stakeholders. On the other hand, some scholarship cautions against treating claim and tactical diversity as positive predictors of movement success. Gamson (1975) and McCarthy and Zald (1977) both suggest that because they are strategic actors, championing multiple causes can make protest groups even more vulnerable to competition from other protest groups seeking attention from the same set of potential supporters. In other words, because protest groups vie for the public's attention, greater specialization in claims ought to benefit protest groups that seek to stand out from the competition. King and Cornwall (2005) find evidence for this perspective by showing how activist groups in the women's suffrage movement resisted the adoption of a wide range of claims and strategies, choosing instead to specialize in specific tactics and claims, leading to increasing returns to learning. Similarly, McVeigh, et al (2004) document how the Ku Klux Klan's more specialized economic framing of their claims resonated more with local populations, leading to greater mobilization.

Addressing the tension about whether specialization or diversity breeds movement success is the main motivation for our analysis. On one side, diversity in claims and tactics can enhance movement success by boosting resource mobilization for protest groups. Conversely, specialization in claims and tactics can also help garner public attention by accentuating contrast between a focal protest and other protests as they compete for public attention. We argue that the main sources of disagreement lie in confusion about the level of analysis and lack of clarity in the definition of movement success. For this reason, we select a setting that in which protest events are systematically observable and success can be reliably measured. In particular, we study whether anti-nuclear energy protest events staged near planned nuclear power plants in the U.S. influence the likelihood of their termination.

\section{Empirical setting: Anti-Nuclear Activism in the U.S.}


Background. The United States has a long tradition of anti-nuclear activism (Giugni 2004; Wellock 1998) rooted in opposition to large-scale energy projects more broadly (McAdam and Boudet 2012; Rucht 1990). Organized collective action against nuclear power first emerged in the 1960s as a spinoff of the movement against nuclear weapons, which itself developed as a response to the nuclear arms race during the Cold War. While the first commercial nuclear power plant was inaugurated in Shippingport, Pennsylvania by President Eisenhower in 1958, protests against nuclear installations had already begun one year earlier in 1957, when the United Auto Workers Union voiced its opposition to the prototype fast breeder reactor Fermi 1 in Newport, Michigan. Other early projected nuclear units were met with similar hostility by activists. A 1958 proposal by Pacific Gas \& Electric for a new plant to be built at Bodega Bay, California, was eventually set aside in 1964 after a large public demonstration led by groups such as the Sierra Club. Another proposed plant to be located in Malibu incurred the same fate a few years later (Wellock 1998). As a result of these early successes, as well as a broader shift in public opinion by the early 1970s, the anti-nuclear movement had gained substantial traction nationwide (Price 1982), and anti-nuclear protests gradually began taking place all over the country. Just when the anti-nuclear movement seemed to be slowing down, however, the perception of nuclear power as an unsafe, runaway technology was further reinforced by several accidents, in particular the Three Mile Island accident in Pennsylvania in 1979 (Sovacool 2008). That same year, over 300,000 people gathered at Battery Park in New York City in the largest anti-nuclear protest to date.

Partly as a consequence of all of the above factors, after an initial peak in orders in the early 1970s, the yearly number of proposed new nuclear units dropped to near zero (Piazza and Perretti 2015). Eventually, almost half of all nuclear reactor units ordered in the United States were cancelled. Historians (Walker 2006) agree that such a high rate of cancellations is due to a complex interplay of factors including anti-nuclear activism, the 1973 oil crisis, as well as cost and time overruns and the demand for electricity growing more slowly than expected. Yet, the precise role of collective action-against the 
backdrop of these other technical and macro-economic factors-in influencing the fate of each single unit under development remains unclear.

Insert Table 1 about here

Some preliminary considerations can be made based on Table 1, which reports the number of proposed units broken down by 1) whether they faced at least one protest within 100 miles of the site before they were completed or cancelled, and 2) whether any nuclear accidents happened within 100 miles in the same time window. A chi-squared test of the values in this table shows that proposed nuclear units were not more likely to be cancelled in the presence of nearby accidents. Conversely, the presence of at least one protest in the vicinity of the site is associated with a significant increase in the likelihood of cancellation. While these patterns do not constitute a causal argument, they nonetheless suggest that, when it comes to shaping the outcome of proposed new nuclear units, we cannot rule out the presence of protest events as a credible factor.

Although anti-nuclear energy activism in the U.S. has traditionally been seen as a largely monolithic movement, actors within the movement were actually characterized by a substantial degree of variance in terms of grievances and strategies (Barkan 1979). For instance, some anti-nuclear SMOs, such as the Clamshell Alliance, focused solely on opposing nuclear power and refrained from championing other issues. Other anti-nuclear movement leaders opted instead to forge a large number of alliances with other movements, collaborating with peace movement groups, anti-Vietnam War protestors, NIMBY activists, and leaders from the women's movement (Meyer and Whittier 1994). In a similar fashion, some anti-nuclear protests showed a high degree of tactical specialization, preferring to focus on just a handful of tactics, while others exhibited more tactical diversity. As such, anti-nuclear 
protests constitute an ideal setting for examining the relationship between protest specialization and protest success.

Defining and measuring success in anti-nuclear energy protests. To account for the protest-level features that make some instances of anti-nuclear energy mobilization more successful than others, we first address what constitutes protest success in our empirical setting. Giugni (1998) argued that even for a specific protest, perceptions of a successful outcome can be heterogeneous. For example, are boycotts of apparel companies that work with sweatshops successful if the targeted companies simply reduce their reliance on sweatshops, or should they required to cut ties altogether for the protest to be considered successful (Briscoe, Gupta, and Anner 2015)? From an empirical standpoint, when the perception of movement success is variable, understanding what aspects of a protest factor into its success becomes even more challenging.

Because different stakeholders put different weights on various movement outcomes as indicators of success, selecting a setting with a clear and achievable protest goal allows researchers to focus on explanatory mechanisms rather than accounting for contingencies due to the nature of the outcome (Giugni 1998). In our study, we collect original data to establish a measure of protest success that is less sensitive to heterogeneous interpretations and does not sample on the dependent variable: the cancellation of a proposed nuclear power unit. In the case of nuclear power, electric utilities file a proposal with the Nuclear Regulatory Commission for the construction of a new nuclear unit at a welldefined location. Construction begins a few months to a few years later and ends five to ten years after that. Therefore, activists have ample time to make their voices heard. Furthermore, since nuclear power units can reliably generate electricity for decades once they start operating, protestors have every incentive to mobilize before a new unit is connected to the grid (Price 1982).

Because the nature of the protest is typically local (McAdam and Boudet 2012), opposition to a specific unit also typically transpires in the form of protest within a certain distance of the unit itself. 
McAdam and Boudet (2012) argue that although anti-nuclear energy activism can take many forms from neighbor canvassing to building take-overs and public gatherings - resistance against energy projects often simultaneously reflects the sentiment of a broader nationwide (or international) movement as well as the interests of a local community. Therefore, even if activism is not explicitly directed at named nuclear power plant sites, the mere presence of anti-nuclear agitation sends a clear message about local collective opposition to the initiation of any such construction activity in the surrounding community (McAdam and Boudet 2012, pp. 132-134). Research on anti-chain store activism utilizes the same logic to connect local protests to the anticipated presence of the organizational entities they oppose (Ingram and Rao 2004). Specifically, resistance against corporate-driven suburban sprawl was directed against spread of big-box retailers, even if the protests themselves did not explicitly articulate specific stores as targets (Ingram and Rao 2004, pp. 450-453). We use the same reasoning to make the inference that protest events that are part of anti-nuclear energy movement were staged to express disapproval of any proposed new nuclear units under development nearby.

Also, because we examine hundreds of instances of protest activity directed at clear targets, we are able to observe success and failure across different regions and time periods. In past work, when variable movement success or mobilization is observable, the limited number of relevant cases were only suitable for a qualitative case comparison rather than a statistical analysis (e.g., Wright and Boudet 2012; McVeigh, et al 2006). Our research design allows us to rely on a sample of sufficient size and quality to generate quantitatively meaningful evidence to support a compelling and generalizable explanation.

Despite the empirical advantages of our context, we also identify an important scope condition for the arguments we develop below. On the one hand, a clear measure of success allows us to focus on how certain features of protest are related to the attainment of protestors' goals. On the other hand, findings from our context might not generalize to other movement settings wherein: a) activists have more ambiguous objectives; b) protest success might be subject to multiple interpretations; or c) goals 
are continuously shifting. For example, collective identity movements often press for policy changes in the interest of protecting civil rights, but many protests aim to change public perceptions about certain social groups (Tilly 2004). When a movement's goals are less obvious, it is more difficult to disentangle whether any progress made by the movement are a result of specific features attached to the movement's protest events or changes in the movement's aims.

\section{Specialization and Diversity in Claims and Tactics: Hypothesis Development}

Claim Specialization. Although there are advantages to hybridity and boundary-spanning when it comes to mobilizing organizational resources for collective action (Heaney and Rojas 2014), we argue that at the protest event level, conveying a clear, univocal message is more important for the achievement of stated protest goals. Indeed, even when multiple protest groups come together as a coalition, the claims they make can either be specific to common grievance (Dixon, Danaher, and Kail 2013) or touch on a diversity of issues (Fisher, Dow, and Ray 2017). Likewise, unitary protest groups can embrace multiple movement goals at protest events (Goss and Heaney 2010). Here, we adopt Hilgartner and Bosk's (1988) public arenas framework to conceptualize social problems as issues competing for public attention, which is a limited resource (McCarthy and Zald 1977, Jones and Baumgartner 2005). Because public arenas have a limited carrying capacity, the presence of competing claims in a single protest event necessarily implies that less attention will be allocated to any given issue.

Therefore, in our context, when protest events advance multiple claims beyond a targeted antinuclear energy claim, we expect the protest event's effectiveness in raising awareness to be reduced, as its main grievance-i.e. the opposition to nuclear power-will be crowded out by the presence of additional claims. In other words, when a protest articulates multiple claims, audience attention to any single claim will be diluted. For example, Gamson (1975) observed that across settings, groups that center their demands around a single issue tend to win more concessions than groups with demands 
across multiple issues, even when they are related to one another (see also King and Cornwall 2005; McCarthy and Zald 1977; Steedly and Foley 1979). ${ }^{1}$

Specialization in a core issue, as opposed to espousing multiple claims, can also lend greater legitimacy to a central grievance, and to the movement behind the protest itself, by binding participants to a singular collective goal (Tarrow 2011). On the one hand, making claims that span different movements might furnish access to additional resources or garner increased attention (Meyer and Whittier 1994; Wang and Soule 2012, 2016); however, this can also diminish the likelihood that a focal activist group projects a distinct message and mission. Failure to differentiate from other protest activity can lower the solidarity among movement participants, which in turn can decrease their commitment to press for social change in the areas most relevant to them. At the protest event level, the articulation of multiple messages that represent different movements can also introduce potential conflicts or confusion about collective identity that might temper the effectiveness of protest activity. Specialization in claims, however, can mitigate the risk of "disagreements about who 'we' are - or should be - [which] can become quite costly taking time and resources away from other activist tasks and even alienating participants or fragmenting a movement" (Reger, Myers, and Einwohner 2008: 3). We therefore argue that articulating claims outside of a core anti-nuclear energy claim made in a protest event near a planned nuclear power plant will diminish the likelihood of the plant being cancelled. Otherwise stated:

Hypothesis 1. The more specialized a protest's claims are, the more likely the protest is to be successful.

\footnotetext{
${ }^{1}$ Our argument does not presuppose that when multiple issues are articulated at a protest event, they are necessarily at odds with one another. Indeed, in the anti-nuclear energy movement, claims related to the peace movement and environmental movement, for example, were often aligned with the demands of anti-nuclear activists, which could be considered instances of frame bridging or extension (Snow and Benford 1992). Our argument instead centers on the perception of protests by potential targets, incumbents, and audiences. When multiple claims are expressed at protest events, this creates the opportunity for multiple interpretations by different constituencies, which might precipitate greater inclusion but also might lead to a crowding out effect.
} 
Tactical Diversity. The choice of tactics also plays an important role in a protest group's success. Much work has focused on how protestors develop and draw on their tactical repertoires (Gamson 1975; Giugni 1998; Tilly 2004). McAdam (1983) theorized about the development of new protest tactics as a dialectic process through which activists try to offset their powerlessness. Recently, Wang and Soule (2016) linked tactical innovation to certain structural positions in the wider network of protest activity, such as boundary-spanning and isolation. Finally, Jung et al. (2014) trace the likelihood of issue bricolage in protest events to the degree of cultural similarity - i.e. tactical overlap-among the participating SMOs. In all, this work assumes that protest actors who are best positioned to adopt new tactics and to develop broader tactical repertoires are also most likely to experience success.

We extend this research by arguing that greater tactical diversity increases the odds of success of an anti-nuclear energy protest event. Unlike claims, which represent the collective demands and identity statements of movement participants, tactics represent the "forms of action" that activists undertake to express these very claims (Tarrow 2011, pg. 98). Indeed, Wang and Soule (2012) demonstrate that tactics are modular across movement boundaries (Tarrow 2011), which suggests that just because a protest might specialize in certain claims, this does not necessarily mean that it will also specialize in tactics. Moreover, a protest that adopts more diverse tactics has a higher likelihood of generating attention (McCarthy and Zald 1977; Tilly 2004). Choosing a wider array of tactics can elevate a protest event's cultural resonance with different constituencies that share related grievances (Oberschall 1973). Broadening a protest's choice of tactics can also create an inclusive space that embraces diversity without the risk of diluting protest goals (Minkoff 1999). Thus, we would expect that planned nuclear power plants are more likely to be cancelled when the protests targeting them exhibit greater tactical diversity because they put greater pressure on politicians and regulators by mobilizing multiple stakeholders.

Hypothesis 2. The more diverse a protest's tactics are, the more likely the protest is to be successful. 
We also propose that the positive effect of tactical diversity on protest success will be stronger for protest events characterized by a relatively narrow range of claims. In other words, protests that deploy multiple tactics are most effective when they push for a specific outcome or champion a particular message. Morris's (1993) analysis of the mobilization during the Civil Rights movement in Montgomery testifies to this logic. Specifically, Morris describes the complex coordination required to devise and carry out a strategy that necessitated the deployment of multiple tactics, which led to the crippling of social order in Montgomery. Although the mobilization of diverse tactics, such as boycotts, sit-ins, and marches, gave strength to the organized protests, the adherence to a specific claim - anti-racial segregation - made the protestors' main target - white business owners - especially vulnerable to these multiple tactics. In fact, the choice to focus on a more specialized demand against local business owners, as opposed to broadening their claims to the national level, was deliberate on the part of movement leaders as a way of enhancing the effectiveness of their multiplex strategies. According to Morris (1993: 634), because protestors were committed to a common cause, this allowed movement leaders to centralize the organization of their protest activity. Centralization facilitated the coordination of deploying multiple tactics, which made their execution more effective.

We argue that the mechanisms described by Morris are generalizable to a broad scope of protest events. Greater tactical diversity benefits protest success even more when protest events articulate more specialized claims because the attention-focusing effect of claim specialization reduces the likelihood that the effectiveness of deploying multiple strategies will be diluted among a larger number of causes. Otherwise stated, we posit that tactical diversity increases the chances of protest success even more when claims are specialized because 1) claim specialization facilitates coordination among protest participants who are committed to a common goal, and 2) the resulting pressure on targets will also be directed towards a unique purpose, rather than being spread among multiple issues. 
Hypothesis 3. The positive effect of tactical diversity on a protest's success increases with greater claim specialization.

Claim Specialization and Nearby Protest Competition. The success and mobilization associated with protest is also sensitive to the structural aspects of the environment in which protest activity is initiated. In our context, anti-nuclear energy protest events take place in a local and well-defined sociopolitical environment. A local community can be conceptualized as a public arena in which social problems compete for attention (Hilgartner and Bosk 1988). Because public attention is a scarce resource, the presence of other protests making claims about different issues can divert attention away from the focal protest, frequently prompting activists to specialize in their claims (Shaked and Sutton 1982). One implication, we argue, is that the returns to claim specialization are greater when protests are staged in environments that are more saturated with other protest activity.

Our logic builds on McCarthy and Zald's (1977) assertion that protest organizations tend to specialize on certain issues so as not to compete with one another over similar audiences, resources, and other forms of public support. They hypothesize that as the density of protest activity increases in any given space, SMOs are more likely to specialize as a strategy for prolonging their survival. Similarly, Soule and King (2008) borrow from resource partitioning theory (Carroll 1985; Carroll and Swaminathan 2000) to develop a similar argument to explain why SMOs specialize when competition becomes more concentrated. Together, this work suggests that specialization in claims ought to be more effective under conditions of greater protest competition.

We therefore build on McCarthy and Zald (1977) and Soule and King's (2008) findings about protest competition to develop two hypotheses about how the extent to which claim specialization facilitates protest success can depend on the presence of nearby protests. Whereas McCarthy and Zald (1977) envision competition as a reflection of the number of different issues and claims championed by protest groups in a given space and time, Soule and King (2008) conceptualize the level of competition 
as the concentration of protest activity within a small set of generalist protest organizations. Because we focus on the protest event as our unit of analysis, we focus on competition as measured by both the claim diversity and concentration of nearby protest events. ${ }^{2}$

Hypothesis 4a. The greater the number of claims made in other nearby protests, the greater the positive effect of claim specialization in the focal protest on protest success.

Hypothesis 4b. The greater the concentration of claims made in other nearby protests, the greater the positive effect of claim specialization in the focal protest on protest success.

\section{Data and Methods}

Data Collection. To test our hypotheses, we designed a quantitative study based on a dataset we assembled from several sources. We obtained information about proposed nuclear reactor units in the U.S. from the Power Reactor Information System (PRIS) online database maintained by the International Atomic Energy Agency (IAEA) and historical documents included in the Nuclear Regulatory Commission's (NRC) Agency-wide Documents Access and Management System (ADAMS). By triangulating these sources, we constructed our core dataset containing the following information for each proposed new nuclear unit approved by the NRC: unit name, plant name, year of order, date of cancellation or connection to the grid, plant location (nearest town and geographic coordinates), county and state. We also include technical information such as nameplate power (in megawatts), type of unit, and manufacturer. After excluding research reactors, we were left with a total of 241 reactor units in the U.S. Additionally, we obtained a list of all 58 nuclear accidents that have occurred in the United States from Sovacool's (2008) database, with information about the date, type of accident, fatalities, and cost (in dollars).

\footnotetext{
${ }^{2}$ Although we suggest that the concentration and diversity of claims in other protests represent protest competition in a given environment, we are careful to suggest that they signal different aspects of competition. In other words, one might suggest that concentration and diversity are inherently positively correlated. However, we argue that it is not necessarily the case they these two features of protest competition co-vary. For example, it is possible for an environment that is exceptionally diverse in terms of the number of claims made to be characterized by both high and low concentration. Similarly, in an environment with very few different claims, the distribution of those claims across protest events in that environment can vary as well.
} 
Information about protests come from a database of 23,000 protest events drawn from daily editions of The New York Times (NYT) between 1960 and 1995 as part of the Dynamics of Collective Action Project. ${ }^{3}$ Each event was content-coded for information about what happened, as well as event size, location, targets, presence of social movement organizations (SMOs), police presence, and whether violence was observed. Most relevant for our project, coders also recorded up to four claims from a list of 170 claims and up to four tactics from a list of 67. To isolate protests opposing nuclear power, however, we only considered those that included the claim "Anti-Nuclear (Power) Movement”, which yielded a subset of 341 protests in our time interval. We compared these reported protest events from The New York Times to protest events reported by other newspapers in the regions in which nuclear power plants were planned and found no major differences in terms of overall coverage. Because the reliance on a single newspaper source for protest data could give rise to geographically-related coverage bias (e.g. see Earl et al. 2004; Myers and Caniglia 2004; Ortiz et al. 2005), we further explore the issue through a separate analysis reported in Appendix A.

Since we are interested in exploring how certain protest event features bear on the outcome of a project, we analyze dyads of protest events and proposed nuclear power units. Matching protest events to proposed nuclear units, however, posed distinct empirical challenges. One, very few protests occurred at the proposed nuclear sites themselves, with most taking place in nearby urban areas. Thus, we constructed protest event-nuclear unit dyads by matching each protest event with all active nuclear unit projects within 100 miles from it. ${ }^{4}$ By active project we mean a unit that has been: 1) ordered from the manufacturer; 2) approved by the NRC; 3) not yet completed or cancelled. We study units that are either planned or under construction but not yet completed because once connected to the grid, nuclear reactors are very rarely shut down, unless their license expires or they encounter serious technical difficulties.

\footnotetext{
${ }^{3}$ For more information, see http://www.dynamicsofcollectiveaction.com .

${ }^{4}$ While 100 miles is a rather substantive distance in certain areas of the country (such as the East), in the Southern and Western United States it is not uncommon to drive 100 miles to reach the nearest major city.
} 
Matching 241 proposed new nuclear units with 341 protest events resulted in 1,172 geographically proximate protest-unit dyads. Because each dyad links an active project with a protest that occurred within 100 miles of it, a specific protest event might appear in multiple dyads, and similarly, a specific nuclear unit might appear in multiple dyads.

We also revisited the newspaper articles from which our data were coded to verify that the protest events in our sample were largely motivated by the construction of nuclear power units nearby. ${ }^{5}$ To be clear, our argument requires that an anti-nuclear energy protest occur near a proposed site for us to consider the protest as expressing opposition to the presence of nuclear power in the community. Thus, a protest event does not need to mention a nuclear power plant site by name for us connect the protest to a nearby site as activism against the site. Nevertheless, out of the 341 protest events in our data, 324 (95\%) named organizational targets, which typically referred to the local governmental authorities, energy companies, contractors, or regulators responsible for making progress on the plant. Even in the 27 events that did not name specific organizational targets, our review found that it was largely implicit in the reporting that activists were concerned about the presence of nuclear power in their community. For instance, an article from July 1, 1979 describes the mobilization efforts of Irene Dickinson, who founded the Citizens Committee for the Protection of the Environment as a community apparatus for channeling anti-nuclear energy demands in Westchester, New York. Dickinson's organization primarily coordinated protests outside local government offices the oversaw the regional jurisdictions in which nuclear power plants were proposed. ${ }^{6}$

Modeling Approach. To exploit of the longitudinal nature of our data, we estimate event-history models of plant cancellation. The peculiarities of our empirical setting, however, make survival analysis

\footnotetext{
${ }^{5}$ In many cases, protest events staged near multiple proposed nuclear sites also tended to mention those sites. For example, in an anti-nuclear energy demonstration in Atlantic City, New Jersey on August 8, 1977, protestors gathered to "set off 1,000 balloons of various colors" to voice opposition to proposed sites in nearby Salem, Forked River, and Oyster Creek ( ("Nuclear Power Foes in Protest at 3 Sites." New York Times. August 1, 1977.

6 “County Is a Staging Area of Nuclear Protest.” New York Times. July 1, 1979.
} 
more challenging because each active project (and therefore each dyad) has two possible exit outcomes: completion, i.e. the unit is connected to the grid, and cancellation, i.e. the project is abandoned, and none of our observations are right-censored. Since an alternative means of exiting the risk-set can preclude the event of interest — in this case, cancellation-from occurring, we use competing-risk regression to model our data (Fine and Gray 1999). This allows us to model the sub-distributions of the competing risks directly. In other words, the model is suitable for examining the occurrence of multiple types of mutually exclusive events, as it models both risks simultaneously.

Sample Selection Bias. Because we are concerned with how certain features of an anti-nuclear protest event might be related to a nearby plant's cancellation, it is possible that our results only hold because of unobserved factors that simultaneously predict a nuclear power plant being near an antinuclear protest (i.e., included in our sample for analysis) and its probability of cancellation. We account for this selection bias using a Heckman two-step approach, in which we first estimate a probit regression model with the entire sample of nuclear power plants we collected (Heckman 1979). The dependent variable in this model is whether an anti-nuclear protest took place near the plant and therefore, whether the plant is included in the sample for our main analysis. We use this model to calculate a value for the inverse Mills ratio for each plant in a protest event-plant dyad in our main analysis sample. We therefore treat the value of the inverse Mills ratio for each plant in a dyad as a control variable in our competing risks models to correct for any selection bias (see Boehmke, Morey, and Shannon 2006).

For this approach to be viable, however, the first step probit model must include at least one instrumental variable that reasonably predicts the inclusion of a nuclear plant in our second step analysis sample (the relevance condition), but does not predict the outcome variable of the second step model (the exclusion restriction) - i.e., the probability of the nuclear plant being cancelled. For our instrumental variable, we use our newspaper data to calculate the number of protest events that only made civil rights related claims between 1960 and 1965 within 100 miles of the eventual site of a nuclear plant. We use 
this time window because the first observed protest against one of the nuclear sites in our data did not occur until 1966; additionally, while the coverage of our protest dataset ends in 1995, no new nuclear units were proposed after that time. In other words, we argue that the intensity of civil rights protest activity in the same area of the proposed nuclear power plant is associated with a higher likelihood that the plant will be opposed by anti-nuclear protest events. With regard to the exclusion restriction, there is little reason to suspect that civil rights activism in the past would have any appreciable effect on whether a nearby nuclear power plant is terminated, given that the anti-nuclear and civil rights movements dealt with separate sets of issues and involved different sets of movement actors.

Concerning the relevance condition, past scholarship on social movement spillover (Meyer and Whittier 1994) - or the diffusion of practices, resources, and rhetoric from one movement to another has argued how the historical legacy of one movement can set the stage for protest activity from a different movement. The civil rights movement, in particular, deeply influenced the formative stages of the women's movement, peace movement, and the anti-nuclear power movement (Hall 2005). One reason for the forging of such cross-movement linkages comes from political process theory (McAdam 1982), which argues that successful activism can create breaches in a local political opportunity structure, which can trigger future activism in other issue areas. Another mechanism comes from scholarship on how informal networks for resource mobilization (Gould 1991) are geographically concentrated (Miller 2000) and often repurposed for multiple social movements as leaders often cross boundaries to form cross-movement alliances (Van Dyke 2003). Finally, evidence exists that participation in the civil rights movement led individuals to channel their activism into other protest activity, with the anti-nuclear power movement benefiting in particular (McAdam 1988: 215-217).

Table 2 reports the results of two probit regression models estimating the effect of past nearby civil rights protest activity between 1960 and 1965 on the probability of a planned nuclear plant being targeted by anti-nuclear protest in the future. Of the 237 planned nuclear power plants in our data, 102 
were targeted by anti-nuclear protests and included in our second step analysis sample. Because we are concerned with the selection of nuclear power plant sites, in the first step probit regression we could only control for time-invariant variables. In particular, we controlled for the type of nuclear power plant, the supplier of the plant's resources, the total power capacity of the plant, the year in which the plant was ordered, and the state in which the plant was located. Model 1 of Table 2 includes only these control variables, and in Model 2, we add the number of civil rights protest events reported between 1960 and 1965 within 100 miles of the nuclear power plant as our measure of past civil rights movement activity. According to Model 2, nearby past civil rights movement activity has a positive and significant effect on the likelihood that a nuclear power plant will be targeted by an anti-nuclear power protest event in the future $(p<.001$, Table 2$)$ and therefore included in our second step regression model. Moreover, based on a likelihood ratio test, the inclusion of nearby past civil rights movement protests offers a significant improvement in model fit over Model 1 in Table 2, which indicates support that the relevance condition for our instrumental variable is satisfied.

Insert Table 2 about here

\section{Variables}

In our analysis, the hazard of the cancellation of the proposed plant for a given protest eventnuclear site dyad is our dependent variable. Specifically, from the day a protest event is initiated against a proposed nearby nuclear energy site, we model the instantaneous probability that its development is terminated. Claim specialization is the main independent variable for Hypothesis 1 . To operationalize this variable, we use a simple count of the number of non-nuclear claims associated with each protest 
event, with a higher number signaling lower claim specialization. ${ }^{7}$ In the Dynamics of Collective Action dataset, coders could assign up to 4 claims (out of 170 possible claims) to a protest event. Because, by design, each of our protest events in our protest-unit dyads has been assigned an "Anti-Nuclear (Power) Movement" claim (in any of the 4 slots in which coders could record claims), we count the number of other claims assigned to the protest event. Our measurement mirrors past approaches with the DoCA dataset that have counted the number of claims in a protest to capture the presence of multiple issues (Wang and Soule 2016, Jung, King, and Soule 2014).

Likewise, to test Hypothesis 2, the main independent variable is tactical diversity, which is operationalized as the number of tactics associated with the focal protest. We test Hypothesis 3 by interacting claim specialization with tactical diversity. Coders could assign up to four distinct tactics to each protest, so our variable ranges from one to four. Hypothesis 4a considers the role of claim diversity in the protest environment, which we measure as the number of unique claims from nearby protest events (i.e. events within 50 miles of the focal protest and taking place in the previous 2 years). Hypothesis $4 \mathrm{~b}$ looks at claim concentration in the protest environment. We operationalize this as the HerfindahlHirschman concentration index (HHI) of claims made by nearby protests:

$$
\sum_{i=1} s_{i}^{2}, s=\frac{n_{i}}{n_{a l l}}
$$

where $n_{i}$ is the number of nearby protests events in which claim $i$ is reported, and $n_{\text {all }}$ is the number of all nearby protest events. ${ }^{8}$

\footnotetext{
${ }^{7}$ By 'non-nuclear claims', we refer to claims other than the anti-nuclear energy claim we use to identify our relevant protest events. In the set of 341 anti-nuclear protest events that were relevant for our sample, 53 (15.5\%) featured non-nuclear claims. Within is set of 53 protest events, 25 non-nuclear claims were coded. Out of the 102 proposed nuclear power plant sites in our sample, $43(44.2 \%)$ were paired with nearby anti-nuclear energy protest events, in which non-nuclear claims were reported.

${ }^{8}$ Because claim diversity and claim concentration in the protest environment were found to be highly correlated, we also estimated models with orthogonalized versions of them (by means of the orthog command in Stata 15), which generated similar results. In addition, we also tested versions of these variables that utilized protests events within 50 miles and 100 miles of the focal event as well as within the past 1 year and 6 months. Using these varying geographical and time cutoffs did not meaningfully affect our results.
} 
For control variables, since protest events might vary in effectiveness depending on their distance from the proposed site, we include the distance between the protest and its associated unit for each dyad in our models. Protest success is also likely to be contingent on the presence of other completed nuclear reactors in operation in the vicinity, which we include as a count variable. Finally, technical considerations might make certain units more likely to be cancelled, for instance, because less mature technologies might be more vulnerable to protest. To control for this, we include dummy variables for the type of nuclear unit being constructed. Finally, we include regional dummies (Northeast, Midwest, South, and West) to account for region-specific effects that might confound our findings.

Other control variables drawn from the Dynamics of Collective Action dataset include variables for the reported presence of violence, counterdemonstrators, and SMOs. Controlling for the number of SMOs, in particular, helps us to rule out any possible conflation between making additional non-nuclear claims and the presence of organizational coalitions. We also add a categorical variable for the number of participants, the protest duration, and length of the New York Times article reporting the protest event (to control for the fact that some protests might receive more media attention than others). Coders could also record whether there was a clearly identifiable target expressed in the protestors' actions, and if so, whether the target was (1) the state, (2) a business, (3) a university or school, (4) a foreign state, (5) a medical facility, (6) an ethnic group, or (7) other. We controlled for both of these target related variables because it is possible that the number of claims expressed at protest event could be conflated with the number of targets identified by protestors. ${ }^{9}$ Finally, to account for the possibility that protests might be more successful when they build on a history of local activism, we include variables for the number of protests in the past two years. Summary statistics are reported in Table 3.

\footnotetext{
${ }^{9}$ This is not to suggest that expressing multiple claims necessarily means isolating multiple targets. Indeed, many collective identity movements seeking justice in different realms of civil society are carried out without any specific target in mind. Similarly, a protest event that targets multiple organizational entities can be focused on a singular issue.
} 
Insert Table 3 about here

\section{Results}

Descriptive Results. Figure 1 chronicles the number anti-nuclear energy protest events reported in The New York Times in our dataset from 1960 through 1995. The trend documented in Figure 1 is consistent with historical accounts of anti-nuclear activism, which attributes its initial rise and diffusion to the movement's links to anti-Cold War and nuclear disarmament protest groups in the 1960s. The peak of anti-nuclear activism occurs in 1979, which is also the year of the Three-Mile Island nuclear reactor accident, the most significant nuclear power plant accident to occur on U.S. soil. The accident galvanized anti-nuclear mobilization, but because far fewer nuclear energy plants were planned after 1979, overall public protest against specific sites also fell in volume.

Insert Figure 1

Despite lower levels of protest activity after 1979, Figure 2 shows that planned nuclear power plant sites that were targeted by anti-nuclear energy protest events were much more likely to be cancelled after 1979 than before 1979. One explanation is that targeting planned nuclear sites through protest activity made them more vulnerable to cancellation after 1979 because the anti-nuclear energy movement itself gained broader support and enjoyed attention not only from mainstream audiences, but also from political elites. Together, Figures 1 and 2 help to make sense of the historical context of the variation in the effectiveness of anti-nuclear energy protests. Net of these era-specific factors, our analysis generates insight into how differences in the claims- and tactics-related features of protests can also affect their fortunes. 
Insert Figure 2

Main Competing Risks Models. Table 4 reports the results of our competing-risks regression models for the hazard of cancellation of the active project associated with each dyad. Model 3 includes just control variables, while Model 4 adds the variables for the number of non-nuclear claims and the number of unique tactics reported at the protest event. Model 5 interacts the number of non-nuclear claims and unique tactics variables. Model 6 includes the interaction between the number non-nuclear claims and claim diversity in the nearby protest environment, and Model 7 adds the interaction between the number of non-nuclear claims and claim concentration in the nearby protest environment. Finally, Model 8 interacts non-nuclear claims and a dummy variable for whether a protest event takes place after 1979 as part of an additional analysis, which we detail below. All models also include as a control variable the inverse Mills ratio from our first step probit regression model as part of the Heckman correction approach. The coefficient of the inverse Mills ratio is statistically significant in each model, which indicates that our results would have suffered from selection bias without accounting for the processes that created our sample of nuclear plants targeted by anti-nuclear power protests.

Insert Table 4 about here

Hypotheses 1 and 2 receive support from Model 4 in Table 4, which simultaneously enter the number of non-nuclear claims and number of tactics in our competing risks models as independent variables. Specifically, given a protest event targeting a planned nuclear power plant site, each additional non-nuclear claim made by the protest decreases the hazard-ratio that the targeted nuclear site is cancelled by $21 \%(\exp (-0.240)=0.786, p<.05$, Model 4 , Table 4$)$. In other words, a protest event is most likely 
to result in a cancellation of a targeted nuclear site if it only makes an anti-nuclear claim, as opposed to incorporating messages representing the claims of other causes.

Model 4 shows that greater tactical diversity significantly improves an anti-nuclear protest event's chances of success, offering support for Hypothesis 2. In particular, each additional unique tactic deployed by a protest event increased the hazard-ratio that its targeted nuclear site will be canceled by $14 \%(\exp (0.131)=1.139, p<.001$, Model 4, Table 4). Consistent with other work, this result demonstrates that protest activity that takes multiple forms poses a greater risk to its intended targets.

Model 5 furthermore gives evidence for Hypothesis 3, which states that the positive effect of tactical diversity on a protest event's chances of success is largely conditional on the protest focusing more on making anti-nuclear energy claims. Indeed, the negative and significant interaction effect between the number of tactics and number of non-nuclear claims illustrates that including more diverse claims in protest weakens the positive effect of deploying multiple tactics on the hazard of a targeted nuclear site's cancellation. To be more precise, whereas the hazard-ratio multiplier of using an additional tactic is almost 1.2 when no non-nuclear claims are made, the presence of two or three non-nuclear claims reduces the same multiplier to 0.8 and 0.6 , respectively.

Models 6 and 7, furthermore, lend credence to Hypotheses 4a and 4b, which suggest that claim specialization is more effective when competition from nearby protests is greater. According to Model 6 in Table 4, when there are no other competing claims from other nearby protests, the hazard-ratio multiplier of making one additional non-nuclear claim is only about $0.68(\exp (-0.380)=0.680, p<.001$, Model 6, Table 4). However, as competition from nearby protest increases - as measured by the number of unique claims articulated in those nearby protests - the negative effect of making an additional nonnuclear claim becomes stronger. This suggests that the positive effect of reducing the number of nonnuclear claims on the cancellation of a targeted nuclear site increases when competition from nearby protests intensifies. The results from Model 7 also support this interpretation. In particular, when 
competition is measured as the concentration of non-nuclear energy claims in nearby protests (following Soule and King 2008), the same pattern emerges - greater concentration further exacerbates the negative effect of a focal protest making additional non-nuclear claims on the cancellation of its targeted nuclear site.

Although our results revealed that pairing additional claims with anti-nuclear energy claims reduces the effectiveness of a protest, in an unreported analysis, we also explored the effects of making specific additional claims. The types of claims that were most often paired with anti-nuclear energy claims in our sample of protest events were those related to the peace movement $(6 \%$ of all protest events), nuclear disarmament (5\%), the environment (5\%), and NIMBY (4\%). In addition, we estimated models that included dummy variables for each type of claim identified above, which revealed that although making additional claims related to nuclear disarmament, the peace movement, or NIMBY reduced the likelihood plant cancellation, making claims related to the environment increased the likelihood of plant cancellation. We speculate that this opposite effect is likely a result of the notion that the anti-nuclear energy movement grew out of the environmental movement, making the claims from these two movements highly similar (Giugni 1997, Rucht 1990). In other words, making a claim about the environment in an anti-nuclear energy protest might confer greater focus on the protest. Controlling for the type of additional claim, however, does not alter the magnitude or statistical significance of the negative effect of the number of additional non-nuclear energy claims.

Finally, to gauge the robustness of our results to alternative explanations and model specifications, we ran a number of additional analyses. These account for: a) cost-based considerations as an alternative explanation for the decision to shut down a nuclear reactor under development; b) the potential endogeneity of our claim specialization variable; and c) the possibility that anti-nuclear protests might have become more effective over time, gaining greater legitimacy as the movement matured. Due to space constraints, robustness checks are presented and discussed in detail in Appendix B. 


\section{Discussion and Conclusion}

We developed a set of arguments about how claim specialization and tactical diversity affect the attainment of protestors' goals. First, our results showed that when anti-nuclear protests articulate additional claims that are not directly related to anti-nuclear issues, they are less effective in obtaining cancellations of targeted nuclear power plant projects. Second, anti-nuclear protests are more successful when they employ a broad range of tactics. We also showed how these effects are mutually reinforcing: the effect of tactical diversity is particularly prominent with greater claim specialization. Finally, our findings underscore the importance of the protest environment in shaping outcomes: greater density in nearby protests tends to enhance the greater probability of protest success that making more specialized claims brings.

Although we have compiled a comprehensive dataset with attractive features for studying the contingencies of social movement success, our results come with limitations. For instance, while social movement success has been defined broadly in the literature, we are unable to study other, complementary facets of it such as local policy changes, which are also relevant. In other words, although one of the strengths of our analysis is that our measure of protest success - the termination of a proposed new nuclear power plant - is systematically observable and clearly associated with the efforts of activists, it also limits our ability to generalize our findings to protest outcomes that do not entail clearly defined organizational targets or explicitly stated goals. In a similar fashion, our data sources only cover collective action that takes place in the public sphere; because we are unable to study other types of protest, our findings likely do not apply to activism that takes the form of private politics (McDonnell, King, and Soule 2015). Related, given that we focus on the U.S. context, differences with the political opportunity structure for anti-nuclear activism in regions such as Europe might also prevent the generalization of our results beyond the U.S. (Rucht 1990). 
Concerning our explanatory variables, one dimension of claim specialization that our measure does not capture concerns the specific goals of the actors involved in protest event. For example, a protest event in which we code a diversity of claims might result from either the involvement of multiple activist groups that each champion a broad range of issues or a coalition of different groups that each specialize in separate issues. The dynamics of collaboration might therefore be different based on how who represents each claim at a multi-issue protest event. For example, a coalition of different specialist SMOs might bring more ardent supporters for each separate issue, but might also face greater coordination costs, lowering their effectiveness in protest. Furthermore, although we interpret the claims reported in our dataset's protest events as individual issues, we did not explore how the use of certain non-nuclear claims might be instances of frame extension or frame bridging (Snow and Benford 1992), which was beyond the focus of our study. Future researchers might therefore extend our findings by investigating the role of who makes certain claims as a process of social movement framing.

Together, our results contribute significantly to a clearer understanding of what makes protests against organizational targets successful. In addition, we show that despite the overall success of the anti-nuclear movement in curtailing the spread of nuclear power plants in the U.S., within the movement itself, protests garnered heterogeneous results. While scholarship attributes the demise of many planned nuclear power plant sites to the presence of protest activity, little work has systematically investigated their outcomes. Ours is the first study to link variables at the protest event level to observable indicators of success in the anti-nuclear context.

Our findings also reveal another dimension of the role of hybridity in social movement protest, which has attracted recent scholarly attention. Wang and Soule (2012), for example, find that social movement organizations that already span many tactical repertoires are likely to adopt new tactics from other SMOs. Heaney and Rojas (2014) further find that if a movement adopts a hybrid identity that cuts across movement claims and groups, they are likely to attract more supporters. However, our results 
show that the benefits of hybridity can come with a trade-off. Specifically, spanning movement categories can also make a particular protest less effective in attaining a desirable outcome. Thus, although recruitment might benefit from hybridity, when articulating grievances, protestors appear to be better served focusing on single issues.

What might be driving our main result that boundary-spanning in claims was detrimental to the objectives of anti-nuclear energy protests? One additional analysis we elaborate in Appendix B reveals that articulating additional non-nuclear claims diminished the likelihood of site termination prior to 1979, the year of the Three Mile Island accident (TMI), but after 1979, making non-nuclear claims at a protest events was positively associated with the hazard of site termination. We speculate that a likely reason was that as a watershed moment, TMI brought mainstream attention to the anti-nuclear power movement, which increased the legitimacy the protest events it staged. Thus, rather than confusing audiences, after 1979, the articulation of claims from adjacent movements became an important signal of legitimacy as anti-nuclear activism gained national prominence (Walker and Stepick 2018). This explanation coheres with Gamson and Modigliani's (1989) account of how media interpretations of the U.S. anti-nuclear movement changed after TMI. Specifically, the accident "accelerated a shift form progress [positive framing] to runaway and devil's bargain [negative framings] as the most popular schemata among the attentive public" (Gamson and Modigliani 1978, pg. 33). The result was the emergence of widespread sensitivity of the health and environmental risks of nuclear power, viewed through a greater diversity of frames. Our findings therefore imply that when a movement is not featured on a national (or international) stage, the inclusion of more diverse claims does not contribute to the perceived legitimacy of its demands.

Moving beyond social movements, our findings also resonate with broader research in sociology on the consequences of boundary-spanning: specifically, whether social actors with focused profilesbe it in terms of characteristics, strategic choices, or goals - have more advantages than less specialized ones (Carroll and Hannan 2000; Zuckerman 1999; Zuckerman et al. 2003). While evidence has been 
issued on both sides, our study corroborates the idea that the benefits of focus are not universal, but hinge on the underlying explanatory mechanism. In the case of social movement claims, specialization is helpful because it draws focused attention to the activists' cause. More generally, we argue that focused profiles work best when standing out from a crowd and attracting the attention of audiences are aspects of primary importance (Hilgartner and Bosk 1988; Hoffman and Ocasio 2001). Conversely, when it comes to tactics, we have shown diversity, not specialization, to be beneficial. Here, employing a plurality of tactics signals the multiplex resources that a protest event can activate to garner broader support and attention. We contribute to this broader literature by highlighting how the advantages of specialization and diversity are contingent on both the audience and the environment of social action.

Finally, from an empirical standpoint, our findings also contribute to the burgeoning literature on “site fights" (e.g. Aldrich 2008; McAdam et al. 2010; McAdam and Boudet 2012; Wright and Boudet 2012) — that is, episodes of contention that emerge as a result of siting decisions by firms, most notably in the context of large energy projects. In turn, understanding when such protest events might be successful in thwarting firm decisions might have useful implications not just for the activists that mobilize in opposition, but also for the firms and policymakers that are behind siting decisions. Given the ever-increasing contentiousness of energy policy (Aldrich 2008) and the growing impact of stakeholder action in this domain (Vasi 2010; Vasi et al. 2015), our findings can inform all interested parties about the odds and likely outcomes of mobilization as a function of both social movement features and the characteristics of the protest environment in the local community. 


\section{References}

Aldrich, Daniel P. 2008. Site Fights: Divisive Facilities and Civil Society in Japan and the West. Ithaca, NY: Cornell University Press.

Barkan, Steven E. 1979. "Strategic, Tactical and Organizational Dilemmas of the Protest Movement against Nuclear Power.” Social Problems 27(1):19-37.

Boehmke, Frederick J., Daniel S. Morey, and Megan Shannon. 2006. "Selection Bias and ContinuousTime Duration Model: Consequences and a Proposed Solution.” American Journal of Political Science 50(1):192-207.

Briscoe, Forrest, Abhinav Gupta, and Mark S. Anner. 2015. "Social Activism and Practice Diffusion: How Activist Tactics Affect Non-Targeted Organizations.” Administrative Science Quarterly 60(2):300-332.

Carroll, Glenn R. 1985. "Concentration and Specialization: Dynamics of Niche Width in Populations of Organizations.” American Journal of Sociology 90(6):1262-83.

Carroll, Glenn R. and Michael T. Hannan. 2000. "Why Corporate Demography Matters: Policy Implications of Organizational Diversity." California Management Review 42(3):148-64.

Carroll, Glenn R. and Anand Swaminathan. 2000. "Why the Microbrewery Movement? Organizational Dynamics of Resource Partitioning in the U.S . Brewing Industry.” American Journal of Sociology 106(3):715-62.

Van Dyke, Nella. 2003. "Crossing Movement Boundaries: Factors That Facilitate Coalition Protest by American College Students, 1930-1990.” Social Problems 50(2):226-50.

Earl, Jennifer, Andrew Martin, John D. McCarthy, and Sarah A. Soule. 2004. "The Use of Newspaper Data in the Study of Collective Action." Annual Review of Sociology 30(1):65-80.

Fine, Jason P. and Robert J. Gray. 1999. "A Proportional Hazards Model for the Subdistribution of a Competing Risk." Journal of the American Statistical Association 94(446):496-509.

Gamson, William A. 1975. The Strategy of Social Protest. Homewood, IL: Dorsey.

Giugni, Marco G. 1998. "Was It Worth The Effort? The Outcomes and Consequences of Social Movements." Annual Review of Sociology 24(1):371-93.

Giugni, Marco G. 2004. Social Protest and Policy Change: Ecology, Antinuclear, and Peace Movements in Comparative Perspective. Lanham, MD: Rowman and Littlefield.

Gould, Roger V. 1991. "Multiple Networks and Mobilization in the Paris Commune, 1871." American Sociological Review 56(6):716-29.

Hall, Simon. 2005. Peace and Freedom: The Civil Rights and Antiwar Movements in the 1960s. Philadelphia, PA, PA: University of Pennsylvania Press.

Heaney, Michael T. and Fabio Rojas. 2014. "Hybrid Activism: Social Movement Mobilization in a Multi-Movement Environment.” American Journal of Sociology 119(4).

Heckman, James J. 1979. “Sample Selection Bias as a Specification Error.” Econometrica 47(1):15361.

Hilgartner, Stephen and Charles L. Bosk. 1988. "The Rise and Fall of Social Problems: A Public Arenas Model.” American Journal of Sociology 94(1):53-78.

Hoffman, Andrew J. and William Ocasio. 2001. "Not All Events Are Attended Equally: Toward a Middle-Range Theory of Industry Attention to External Events." Organization Science 12(4):41434.

Isaac, Larry and Lars Christiansen. 2002. "How the Civil Rights Movement Revitalized Labor Militancy." American Sociological Review 67(5):722. 
Isaac, Larry, Steve McDonald, and Greg Lukasik. 2006. “Takin' It from the Streets: How the Sixties Mass Movement Revitalized Unionization.” American Journal of Sociology 112(1):46-96.

Jung, Wooseok, Brayden G. King, and Sarah A. Soule. 2014. "Issue Bricolage: Explaining the Configuration of the Social Movement Sector, 1960-1995.” American Journal of Sociology 120(1):187-225.

King, Brayden G. and Marie Cornwall. 2005. "Specialists and Generalists: Learning Strategies in the Woman Suffrage Movement, 1866-1918.” Research in Social Movements, Conflicts, and Change 26:3-34.

Komanoff, Charles. 1982. Power Plant Cost Escalation: Nuclear and Coal Capital Cost, Regulation, and Economics. Van Nostrand Reinhold.

Koomey, Jonathan G. and Nathan E. Hultman. 2007. "A Reactor-Level Analysis of Busbar Costs for US Nuclear Plants, 1970-2005.” Energy Policy 35(11):5630-5642.

Lindekilde, Lasse. 2013. "Claims-Making." in The Wiley-Blackwell Encyclopedia of Social and Political Movements. Oxford, UK: Blackwell Publishing Ltd.

McAdam, Doug. 1982. Political Process and the Development of Black Insurgency, 1930-1970. Chicago, IL: University of Chicago Press.

McAdam, Doug. 1983. "Tactical Innovation and the Pace of Insurgency." American Sociological Review 48(6):735-54.

McAdam, Doug. 1988. Freedom Summer. Oxford, UK, UK: Oxford University Press.

McAdam, Doug et al. 2010. "'Site Fights': Explaining Opposition to Pipeline Projects in the Developing World." Sociological Forum 25(3):401-27.

McAdam, Doug and Hilary Boudet. 2012. Putting Social Movements in Their Place: Explaining Opposition to Energy Projects in the United States, 2000-2005. Cambridge, UK: Cambridge University Press.

McAdam, Doug and Yang Su. 2002. "The War at Home: Antiwar Protests and Congressional Voting, 1965 to 1973." American Sociological Review 67(5):696-721.

McCarthy, John D. and Mayer N. Zald. 1977. "Resource Mobilization and Social Movements: A Partial Theory." American Journal of Sociology 82(6):1212-41.

McDonnell, Mary-Hunter, Brayden G. King, and Sarah A. Soule. 2015. "A Dynamic Process Model of Private Politics: Activist Targeting and Corporate Receptivity to Social Challenges." American Sociological Review 80(3):654-78.

McVeigh, Rory, Daniel J. Myers, and David Sikkink. 2004. "Corn, Klansmen, and Coolidge: Structure and Framing in Social Movements." Social Forces 83(2):653-90.

Meyer, D. S. and N. Whittier. 1994. "Social Movement Spillover." Social Problems 41:277-98.

Miller, Byron A. 2000. Geography and Social Movements: Comparing Antinuclear Activism in the Boston Area. University of Minnesota Press.

Minkoff, Debra C. 1999. "Bending with the Wind: Strategic Change and Adaptation by Women's and Racial Minority Organizations.” American Journal of Sociology 104(6):1666-1703.

Minkoff, Debra C. 2002. "The Emergence of Hybrid Organizational Forms: Combining Identity-Based Service Provision and Political Action.” Nonprofit and Voluntary Sector Quarterly 31(3):377401.

Morris, Aldon D. 1993. "Birmingham Confrontation Reconsidered: An Analysis of The Dynamics and Tactics of Mobilization." American Sociological Review 58(5):621-36.

Myers, Daniel J. and Beth Schaefer Caniglia. 2004. "All the Rioting That's Fit to Print: Selection Effects in National Newspaper Coverage of Civil Disorders, 1968." American Sociological 
Review 69(4):519-43.

Oberschall, Anthony. 1973. Social Conflict and Social Movements. Englewood Cliffs, NJ: PrenticeHall.

Olzak, Susan and Emily Ryo. 2007. "Organizational Diversity, Vitality and Outcomes in the Civil Rights Movement." Social Forces 85(4):1561-91.

Ortiz, David G., Daniel J. Myers, N.Eugene Walls, and Maria-Elena D. Diaz. 2005. "Where Do We Stand with Newspaper Data?" Mobilization 10(3):397-419.

Piazza, Alessandro and Fabrizio Perretti. 2015. "Categorical Stigma and Firm Disengagement: Nuclear

Power Generation in the United States, 1970-2000.” Organization Science 26(3):724-42.

Price, Jerome. 1982. The Antinuclear Movement. Boston, MA: Twayne.

Reger, Jo, Daniel J. Myers, and Rachel L. Einwohner. 2008. Identity Work in Social Movements.

Rucht, Dieter. 1990. "Campaigns, Skirmishes and Battles: Anti-Nuclear Movements in the USA,

France and West Germany." Organization \& Environment 4(3):193-222.

Shaked, Avner and John Sutton. 1982. "Price Competition Through Product Differentiation." Review of Economic Studies 49(1):3-13.

Soule, Sarah A. and Brayden G. King. 2008. "Competition and Resource Partitioning in Three Social Movement Industries.” American Journal of Sociology 113(6):1568-1610.

Sovacool, Benjamin K. 2008. "The Costs of Failure: A Preliminary Assessment of Major Energy Accidents, 1907-2007.” Energy Policy 36(5):1802-20.

Staggenborg, Suzanne. 1988. "The Consequences of Professionalization and Formalization in the ProChoice Movement.” American Sociological Review 53(4):585.

Steedly, Homer R. and John W. Foley. 1979. "The Success of Protest Groups: Multivariate Analyses." Social Science Research 8(1):1-15.

Tarrow, Sidney. 2011. Power in Movement: Collective Action, Social Movements and Politics.

Cambridge, UK: Cambridge University Press.

Taylor, Verta A. and Nella Van Dyke. 2004. ““"'Get Up, Stand Up”': Tactical Repertoires of Social Movements.” Pp. 262-93 in The Blackwell Companion to Social Movements, edited by D. A.

Snow, S. A. Soule, and H. Kriesi. Blackwell.

Tilly, Charles. 2004. Social Movements, 1768-2004. Boulder, CO: Paradigm.

Vasi, Ion Bogdan. 2010. Winds of Change: The Environmental Movement and the Global Development of the Wind Energy Industry. Oxford, UK: Oxford University Press.

Vasi, Ion Bogdan, Edward T. Walker, John S. Johnson, and Hui Fen Tan. 2015. "'No Fracking Way!'

Documentary Film, Discursive Opportunity, and Local Opposition against Hydraulic Fracturing in the United States, 2010 to 2013." American Sociological Review 80(5):934-59.

Walker, Edward T., and Lina Stepick. 2018. "Valuing the Cause: A Theory of Authenticity in Social Movements." Mobilization. Forthcoming.

Walker, J.Samuel. 2006. Three Mile Island: A Nuclear Crisis in Historical Perspective. Berkeley, CA: University of California Press.

Wang, Dan J. and Alessandro Piazza. 2016. "The Use of Disruptive Tactics in Protest as a Trade-Off: The Role of Social Movement Claims.” Social Forces 94(4):1675-1710.

Wang, Dan J., Alessandro Piazza, and Sarah A. Soule. 2018. "Boundary-Spanning in Social Movements: Antecedents and Outcomes.” Annual Review of Sociology 44(1):167-87.

Wang, Dan J. and Sarah A. Soule. 2012. "Social Movement Organizational Collaboration: Networks of 
Learning and the Diffusion of Protest Tactics, 1960-1995." American Journal of Sociology 117(6):1674-1722.

Wang, Dan J. and Sarah A. Soule. 2016. "Tactical Innovation in Social Movements: The Effects of Peripheral and Multi-Issue Protest." American Sociological Review 81(3):517-48.

Wellock, Thomas. 1998. Critical Masses: Opposition to Nuclear Power in California, 1958-1978. The University of Wisconsin Press.

Wills, John. 2006. Conservation Fallout: Nuclear Protest at Diablo Canyon. Reno, NV: University of Nevada Press.

Wooldridge, Jeffrey M. 2002. Econometric Analysis of Cross Section and Panel Data. Cambridge, MA: The MIT Press.

Wright, Rachel A. and Hilary Schaffer Boudet. 2012. "To Act or Not to Act: Context, Capability, and Community Response to Environmental Risk." American Journal of Sociology 118(3):728-77.

Zuckerman, Ezra W. 1999. "The Categorical Imperative: Securities Analysts and the Illegitimacy Discount." American Journal of Sociology 104(5):1398-1397.

Zuckerman, Ezra W., Tai-Young Kim, Kalinda Ukanwa, and James von Rittmann. 2003. "Robust Identities or Nonentities? Typecasting in the Feature Film Labor Market." American Journal of Sociology 108(5):1018-73. 


\section{Appendix A}

Although the Dynamics of Collective Action (DOCA) dataset's collection of protest events has been used extensively by scholars to chronicle movement activity in the United States (McAdam and Su 2002; Olzak and Ryo 2007; Soule and King 2008; Wang and Soule 2012, 2016), recent work has called on researchers to take greater caution in interpreting results that come from the analysis of newspaper data alone (Ortiz et al. 2005). To deal with the issues of coverage bias and description bias, the DOCA protest event data collection process relied on the documentation and coding of the actual text of New York Times articles, rather than pre-categorized indexes. However, this does not address the concern that the articles upon which the DOCA data were built come from a single publication, which according to Myers and Caniglia (2004), can lead to geographic bias in reporting - specifically, an over-reporting of New York based events and an under-reporting of events elsewhere. For example, Ortiz et al. 2005: (409411) show that NY Times coverage of riot-based protest events decreased with the distance of the event to New York City.

There is no simple solution to the issue of relying on a single source, but Ortiz et al. (2005) recommend taking certain steps to acknowledge and analyze the extent to which relying on protest event data that come from a single newspaper might bias one's results. In our case, we do not expect the $N Y$ Times to have reported every instance of protest against the each of the nuclear sites in our dataset. However, rectifying potential coverage bias would entail exhaustive archival searches of all reporting activity for the regions in which our nuclear sites are situated, a nearly impossible task since many regional newspapers lack electronic full-text historical records. If indeed, protests against nuclear power plants outside of New York receive systematically less coverage from the NY Times, we should expect that the NY Times would under-report protest events directed at these more distant nuclear sites.

To determine the extent of coverage bias in our data, we used Lexis-Nexis to conduct searches across 50 different national and regional newspapers in North America for reports of any protest activity 
in the 55 unique locations where our 102 nuclear sites were situated that was not already reported by the NY Times. For each nuclear site, we bounded our search using a date range from 1960 to 1995 (our period of study), and used broad search terms that only include nuclear site's location name, state, and the term “nuclear". These search terms yielded 2,281 articles across these 55 locations, which we read to observe any protest activity not reported by the NY Times. Full results are available from the authors, but are omitted here to conserve space.

Out of these 55 locations, we located additional reports of protest activity not covered by the $N Y$ Times for 9 locations. A reading of these additional reports showed that most protest events not covered by the NY Times were typically 'follow-on' protests that perpetuated an initial protest that was reported by the NY Times. This was especially the case for Seabrook, for which we found an additional 15 protest events that were not in the 54 protest events near Seabrook in our NY Times dataset. Adding in the protest event data from these four reports did not alter our results when we re-estimated our models. We also estimated models that removed nuclear sites for which there were at least two additional protest events not reported by the NY Times (Seabrook and Susequehanna), which did not alter our results. In addition, we found no instances of non-NY Times reports that contradicted information contained in the NY Times reports of protest events for these 9 sites. Moreover, we found similar reports from other national and regional newspapers confirming key details of the protest events already reported by the NY Times.

It is of course possible that the universe of electronically searchable newspaper records itself does not constitute a representative sample of protest activity. Indeed, Myers and Caniglia (2004) point out that although incorporating more sources can help fill in gaps in reporting, sometimes drawing from multiple newspapers might exacerbate existing coverage bias. As such, our analysis is not meant to completely eliminate doubt in the interpretation of our results, but instead to give readers a more precise understanding of the data generating process. 


\section{Appendix B}

Instrumental Variable Analysis. Although the estimated competing risks models reported in Table 3 offer evidence consistent with our hypotheses, these models also assume that our main independent variable of interest, a protest event's claim specialization, is not endogenous (Wooldridge 2002). If it were endogenous, this would mean that there exists some confounding factor that our models do not control for, which can lead to omitted variable bias in our results. In particular, we might not be accounting for some unobserved factor that simultaneously makes a protest event more likely to make specialized claims and increases the likelihood that its targeted nuclear site is cancelled. For example, it is possible that protest groups intending only to make a specialized anti-nuclear energy claim strategically target nuclear energy sites that they know to be more vulnerable to cancellation. Because we cannot reliably account for the perceived vulnerability of a nuclear site, much less the process by which protestors select nuclear energy units as targets, we do not know whether our measure of claim specialization in our model is endogenous.

To mitigate the concern that claim specialization is endogenous in our models, we adopt an instrumental variable estimation approach, which we describe in Formulas 1 and 2 below (Wooldridge 2002). Specifically, we identify an instrumental variable $Z$, which reasonably predicts variation in our main independent variable of interest $X$ (the relevance assumption) while being uncorrelated with the error term $U$ of an ideal non-endogenous model predicting our dependent variable $Y$ (the exclusion restriction). We then estimate a model that includes $Z$ as an independent variable to predict $X$, which we use to generate predicted values $\hat{X}$ for each of our observations. In principle, the variation of the predicted values of the independent variable is no longer correlated with other confounding variables that might simultaneously predict our dependent variable. Finally, we use these predicted values $\hat{X}$ to replace $X$ in a new estimation of a model that predicts $Y$.

$$
Y_{i}=\beta_{1} X_{i}+\beta_{2} M_{i}+U_{i}
$$




$$
\widehat{X}_{i}=\beta_{3} Z_{i}+\beta_{4} W_{i}+\gamma
$$

In our analysis, we use the number of nearby nuclear power plant accidents to have occurred in the two years prior to a protest event as an instrumental variable. To satisfy the relevance assumption, we argue that the anti-nuclear energy protest events are more likely to make more diverse claims in the immediate aftermath of an accident at a nearby nuclear power plant. This is because we expect the presence of nearby accidents to bring the risk associated with producing nuclear energy to the attention of movement groups, such as peace and environment, other than core anti-nuclear energy activists.

With regard to the exclusion restriction, which is statistically untestable, we argue that planned nuclear power plants are almost never terminated because past accidents reveal a technological deficiency in the plant. In other words, whether nearby nuclear power plants experience accidents has nothing to do with whether the development of a focal nuclear power plant site is discontinued. This is because nearly every documented accident at a nuclear power plant can be attributed to human error, which is for the most part, is impossible to predict (Sovacool 2008). In other words, because the risk of technology failure in leading to a nuclear accident is infinitesimal and the occurrence of human error is largely random and improbable, whether a nuclear accident occurs would not be reason enough to halt the construction of a nearby power plant.

Insert Table B1 about here

Table B1 reports the results for our first stage Poisson model, which we use to predict the number of non-nuclear claims at a given protest event for each of our 1172 protest event-nuclear site dyads. We use a Poisson model because our dependent variable in this first stage model is a count variable that ranges from 0 to 3 . The positive and significant coefficient for the number of nearby nuclear accidents $(\mathrm{p}<.001$, Model 1, Table B1) confirms that the relevance assumption is supported in our analysis. In other words, we do not consider the number of nearby accidents to be a weak instrument. We then use 
the predicted values for non-nuclear claims as an independent variable in our second stage model, which is a similarly specified competing risks model (as in Model 4 of Table 4).

Here, we find that according to Model 2 in Table B1, the instrumented non-nuclear claims variable has a significant and negative effect on the likelihood of nuclear site cancellation, which is consistent with our results in Table 4. We also observe that the magnitude of the instrumented nonnuclear claims variable's effect is far greater than that we obtained for the non-instrumented non-nuclear claims variable in Table 4. We attribute this difference to the smaller amount of variation captured by the instrumented version of this independent variable, which can lead to larger effect sizes. Together, these results suggest that claim specialization in a protest event exerts an independent effect on protest success.

Cost-based alternative explanations. An additional important robustness check concerns the role that capital costs play in the decision to complete or cancel a proposed nuclear reactor unit. If we were to observe that cancelled units are systematically more expensive to build than completed units, we might reasonably conclude that the effect of protests on firm decisions is marginal, which would largely invalidate our arguments. To address this issue, we turned to cost data collected by Komanoff (1982) and Koomey \& Hultman (2007) to construct capital cost estimates for 84 proposed reactor units in our sample; of these, 74 units were ultimately completed, while 10 were cancelled. While the sample is unbalanced and its coverage is partial, to our knowledge, these are the only available sources of capital cost information on nuclear reactors in the United States. ${ }^{10}$ After calculating a capital cost estimate for each of the 84 reactors in the subsample, we found that the cancelled units were not significantly more expensive than the completed units, which corroborates the idea that cost-based explanations alone cannot account for our observed pattern of results. ${ }^{11}$

${ }^{10}$ We estimated capital costs based on the formula in Komanoff (1982:199). Further details are available from the authors. 11 Cancelled units: mean $=751.7 ; \mathrm{SD}=106.8$. Completed units: mean $=697.0, \mathrm{SD}=206.2$. Test statistics: $\mathrm{t}(82)=0.82, \mathrm{p}=$ .4142 
Era-Specific Analysis. Finally, although our analysis has controlled for a number of factors related to the protest environment, Figure 2 revealed that nuclear sites targeted by protests were more likely to be terminated over time. One possible reason is that anti-nuclear energy protests gained greater legitimacy as the movement matured, making any associated protest more effective overall (Staggenborg 1988). To explore this possibility, we exploit this time variation by dividing our analysis into two time periods - prior to and after 1979, the year of the Three Mile Island (TMI) nuclear reactor accident, a commonly recognized watershed moment in anti-nuclear activism (Walker 2006, Gamson and Modigliani 1989). More specifically, we analyze the conditional effect of claim specialization on protest success by interacting it with a dummy variable for whether the protest event was staged after TMI in 1979.

Model 8 in Table 4 shows that prior to 1979, making an additional non-nuclear claim lowered the hazard-ratio of cancellation by $9 \%(\exp (-0.091)=0.913$, Model 8, Table 4) whereas after 1979 articulating an additional non-nuclear claim increased the hazard-ratio of cancellation by $27 \%(\exp (-$ $0.091+0.329)=1.269$, Model 8, Table 4). In other words, our results from Model 6 are consistent with the interpretation that especially after 1979, the movement enjoyed enough mainstream support that the benefits of allying with other movement groups and messages outweighed the risk it posed to the coherence and unity of the anti-nuclear energy movement's central claim. 
Table 1. Contingency tables and chi-square tests of the correlation between nearby protests/accidents (within 100 miles) and the outcome of planned nuclear projects.

\begin{tabular}{r|cc|c} 
& No protest & Protest & Total \\
\hline Completed & 99 & 30 & 129 \\
& $(76.7 \%)$ & $(26.8 \%)$ & $(53.5 \%)$ \\
Cancelled & 30 & 82 & 112 \\
& $(23.3 \%)$ & $(73.2 \%)$ & $(46.5 \%)$ \\
\hline Total & 129 & 112 & $\begin{array}{l}\text { 241 planned } \\
\text { nuclear sites }\end{array}$
\end{tabular}

Chi-squared
test:

\begin{tabular}{r|cc|c} 
& No accident & Accident & Total \\
\hline Completed & 101 & 28 & 129 \\
& $(53.2 \%)$ & $(54.9 \%)$ & $(53.5 \%)$ \\
Cancelled & 89 & 23 & 112 \\
& $(46.8 \%)$ & $(45.1 \%)$ & $(46.5 \%)$ \\
\hline Total & 190 & 51 & $\begin{array}{c}\text { 241 planned } \\
\text { nuclear sites }\end{array}$
\end{tabular}

Chi-squared
test:

Note: Row percentages within columns are shown in parentheses in each cell. 
Table 2. Estimated coefficients from probit regression of proposed nuclear site being targeted by anti-nuclear energy protest

\begin{tabular}{lll} 
Variable & \multicolumn{1}{c}{ Model 1 } & \multicolumn{1}{c}{ Model 2} \\
\hline Power Type = "PWR" & -1.936 & -2.255 \\
& $(5.917)$ & $(12.040)$ \\
Supplier = B\&W & 0.803 & 0.963 \\
& $(9.616)$ & $(19.391)$ \\
Supplier = CE & 2.209 & 2.621 \\
& $(9.622)$ & $(19.404)$ \\
Supplier = GE & -1.003 & -0.962 \\
& $(7.596)$ & $(15.213)$ \\
Supplier = W & 1.057 & 1.224 \\
& $(9.612)$ & $(19.393)$ \\
Unit Power & $0.009 * * *$ & $0.009 * * *$ \\
& $(0.001)$ & $(0.002)$ \\
Year Nuclear Site was Ordered & $-0.244^{* * *}$ & $-0.197 * *$ \\
& $(0.067)$ & $(0.073)$ \\
Number of Civil Rights Protest Events within 50 miles of site, $1960-$ & & $0.006^{* * *}$ \\
1965 & & $(0.002)$ \\
\hline n (nuclear sites) & 237 & 237 \\
Log Likelihood & -61.476 & -58.322 \\
\hline
\end{tabular}

$* \mathrm{p}<.05, * * \mathrm{p}<.01, * * * \mathrm{p}<.001$ (two-tailed tests)

Note: Reference group for Supplier $=$ 'Other'. Dummy variables for state of nuclear site included in models, but not displayed to conserve space. Inverse Mills Ratio for second-step regression model is calculated using Model 2 above. 
Table 3. Summary Statistics for Variables Used in Analysis

Variable

Mean

SD

Additional Notes

Nuclear Site Level Variables ( $\mathrm{n}=102$ nuclear sites)

Construction cancelled

Unit power (in megawatts)

.57

1097.89

.29

Boiling Water Reactor (BWR)

High Temperature Gas Cooled (HTGC)

Pressurized Water Reactor (PWR)

Region (in U.S.)

Northeast

Midwest

South

West

Number of Nearby Active Nuclear Energy Power Plants

Protest Event Variables $(n=297$ protest events)

Number of non-anti-nuclear energy claims

Number of tactics

Disruptive tactics used

Property damage reported

Violence reported

Counterdemonstrators reported

Number of SMOs present

Duration (in days)

Length of article reporting event (in paragraphs)
.02

.69

.25

.29

.11

Independent Variable: Claim Specialization

Independent Variable: Tactical Diversity

$\mathrm{SMO}=$ Social

0.75

(1.11)

Movement

Organizations 
Protest near big city

Nuclear Site Protest Event Dyad Variables ( $\mathrm{n}=1178$ dyads)

Number of claims in nearby protests

Concentration of claims in nearby protests

(Herfindahl Index of Concentration)

Number of nearby protests 1

Distance between protest and nuclear site (in miles)
Within 50 miles of a city with

population $>1$ million

at time of protest

Independent Variable:

Nearby Protest

Competition

Independent Variable:

0.08

$(0.15)$

Nearby Protest

Competition

${ }^{1}$ Nearby refers to protests occurring within 50 miles of either the protest event or nuclear site in the past two years 
Table 4. Competing Risks Regression of Nuclear Site Being Cancelled on Selected Independent Variables

\begin{tabular}{|c|c|c|c|c|c|c|}
\hline Variable & Model 3 & Model 4 & Model 5 & Model 6 & Model 7 & Model 8 \\
\hline \multirow{2}{*}{ Non-anti-nuclear energy claims } & & $-0.240 *$ & 0.058 & $-0.385 * * *$ & $-0.795 * * *$ & $-0.091 * *$ \\
\hline & & $(0.104)$ & $(0.204)$ & $(0.108)$ & $(0.195)$ & $(0.029)$ \\
\hline \multirow{2}{*}{ Number of tactics } & & $0.131 * * *$ & $0.159 * * *$ & $0.121 * * *$ & $0.120 * * *$ & $0.137 * * *$ \\
\hline & & $(0.029)$ & $(0.032)$ & $(0.020)$ & $(0.019)$ & $(0.016)$ \\
\hline \multirow{2}{*}{ Non-anti-nuclear energy claims $\times$ Number of Tactics } & & & $-0.166 * *$ & & & \\
\hline & & & $(0.060)$ & & & \\
\hline \multirow{2}{*}{ Number of claims in nearby protests (logged) } & & & & $-0.116^{* * *}$ & & \\
\hline & & & & $(0.021)$ & & \\
\hline \multirow{2}{*}{ Non-anti-nuclear energy claims $\times$ Number of claims in nearby protests (logged) } & & & & $-0.062 * * *$ & & \\
\hline & & & & $(0.012)$ & & \\
\hline \multirow[t]{2}{*}{ Concentration of claims in nearby protests } & & & & & $-0.325^{* * *}$ & \\
\hline & & & & & $(0.048)$ & \\
\hline \multirow{2}{*}{ Non-anti-nuclear energy claims $\times$ Concentration of claims in nearby protests } & & & & & $-0.147 * * *$ & \\
\hline & & & & & $(0.030)$ & \\
\hline \multirow{2}{*}{ Protest occurred after Three-Mile Island Accident } & & & & & & $-1.932 * * *$ \\
\hline & & & & & & $(0.116)$ \\
\hline \multirow[t]{2}{*}{ Non-anti-nuclear energy claims $\times$ After Three-Mile Island Accident } & & & & & & $0.329 * * *$ \\
\hline & & & & & & $(0.077)$ \\
\hline \multirow{2}{*}{ Unit Power } & $0.004 * * *$ & $0.004 * * *$ & $0.004 * * *$ & $0.004 * * *$ & $0.005^{* * *}$ & $0.004 * * *$ \\
\hline & $(0.000)$ & $(0.000)$ & $(0.000)$ & $(0.000)$ & $(0.000)$ & $(0.000)$ \\
\hline \multirow{2}{*}{ Unit Type $=$ PWR } & $6.392^{* * *}$ & $6.403 * * *$ & $6.415^{* * *}$ & $6.220 * * *$ & $6.169 * * *$ & $5.505^{* * *}$ \\
\hline & $(1.449)$ & $(1.399)$ & $(1.392)$ & $(1.494)$ & $(1.455)$ & $(1.423)$ \\
\hline \multirow[t]{2}{*}{ Region $=$ Midwest } & -0.059 & -0.052 & -0.038 & 0.154 & 0.191 & 0.184 \\
\hline & $(0.348)$ & $(0.324)$ & $(0.316)$ & $(0.237)$ & $(0.260)$ & $(0.130)$ \\
\hline \multirow{2}{*}{ Region $=$ South } & $0.888^{* * *}$ & $0.886^{* * *}$ & $0.883 * * *$ & $0.906 * * *$ & $0.964 * * *$ & $0.514 * * *$ \\
\hline & $(0.145)$ & $(0.155)$ & $(0.155)$ & $(0.135)$ & $(0.134)$ & $(0.031)$ \\
\hline \multirow{2}{*}{ Region $=$ West } & $-2.056^{* * *}$ & $-2.057 * * *$ & $-2.067 * * *$ & $-1.874 * * *$ & $-1.673 * * *$ & $-2.145^{* * *}$ \\
\hline & $(0.138)$ & $(0.137)$ & $(0.135)$ & $(0.150)$ & $(0.153)$ & $(0.095)$ \\
\hline Number of Nearby Active Nuclear Energy Power Plants & $-0.201 * *$ & $-0.204 * *$ & $-0.204 * *$ & $-0.225^{* * *}$ & $-0.222 * * *$ & $-0.330 * * *$ \\
\hline
\end{tabular}




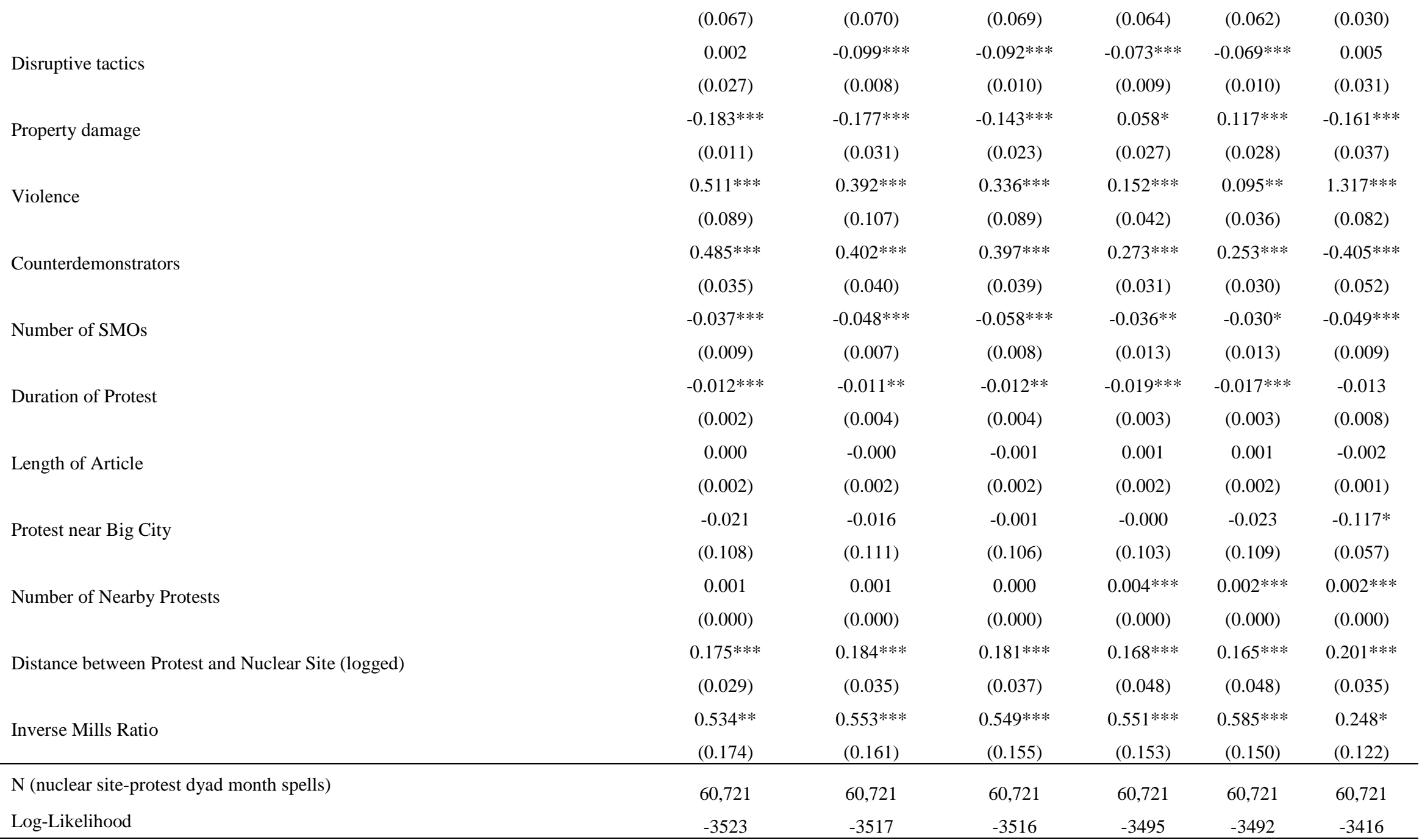

$* \mathrm{p}<.05, * * \mathrm{p}<.01, * * * \mathrm{p}<.001$ (two-tailed tests)

Note : Event of interest $=$ Nuclear site cancellation, Competing event $=$ Nuclear site completion. We only included one dummy variable for Unit Power Type because only three nuclear sites were of the HTGC power type. Standard errors have been estimated using two-way clustering at the Nuclear Site and Protest Event levels. 


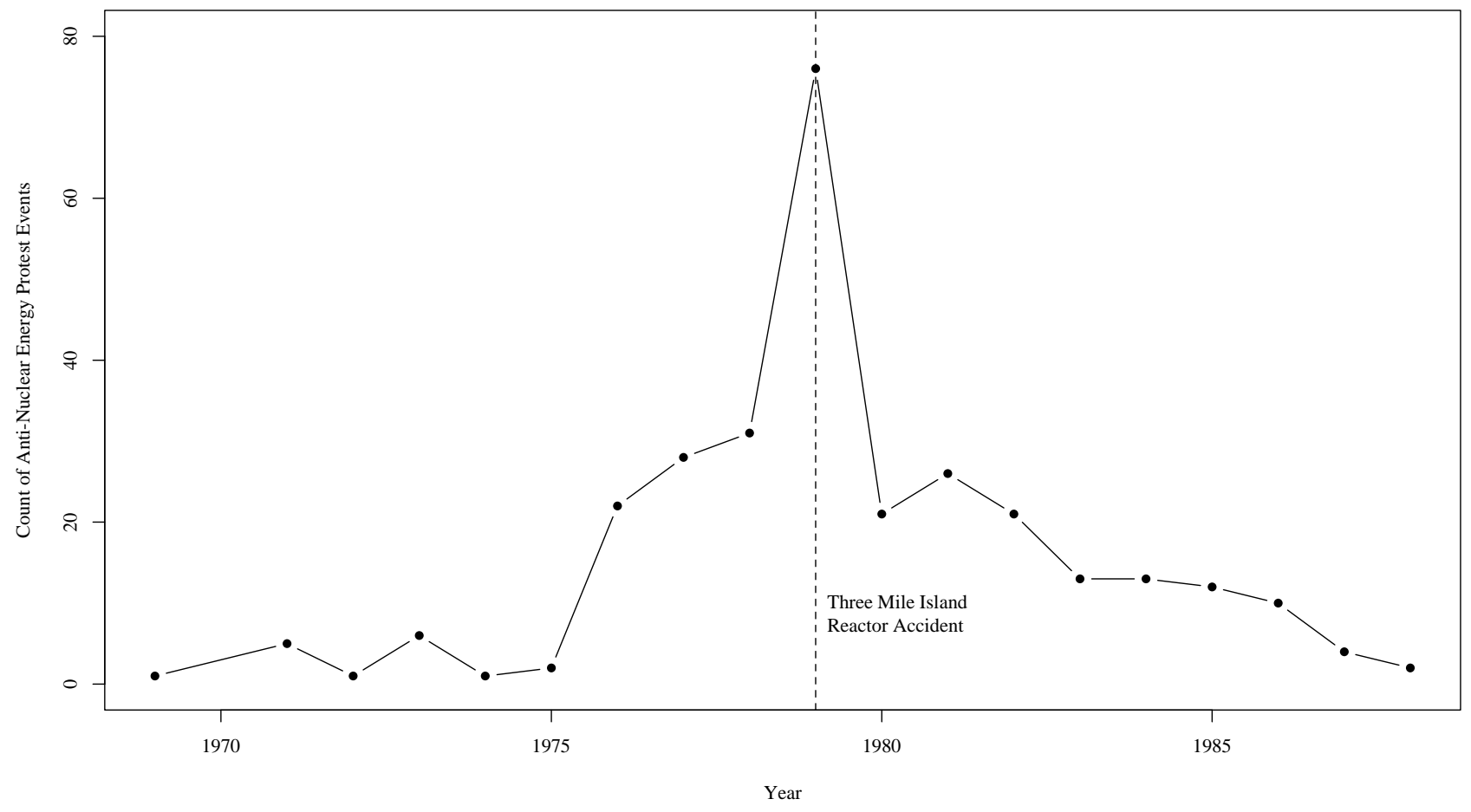

Figure 1. Anti-Nuclear Energy Activism Targeting Planned Nuclear Power Plants in the U.S., 19671988 


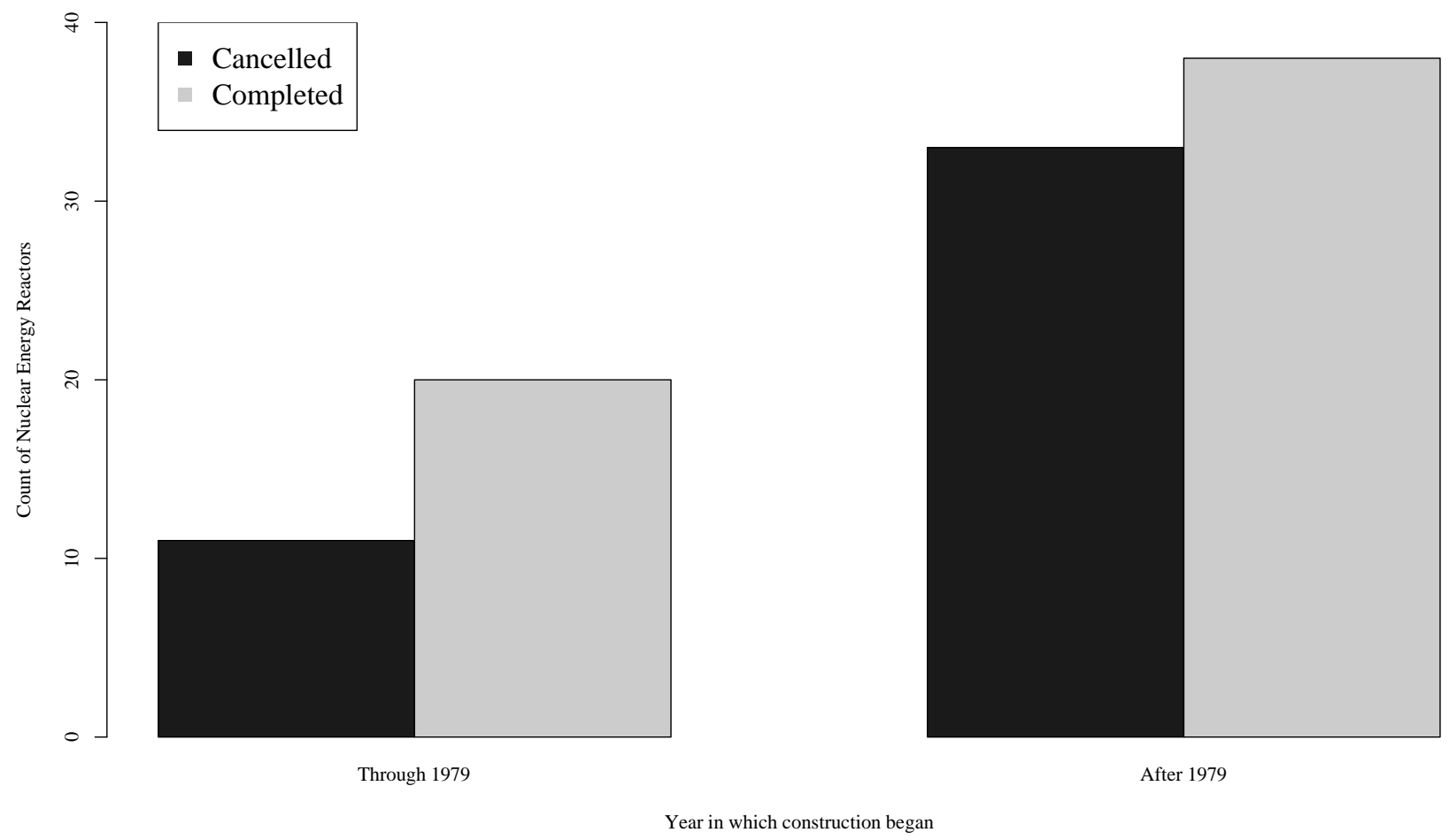

Figure 2. Outcomes of Nuclear Energy Reactors Targeted by Protest Events, 1967-1995.

Note: Each bar represents a count of the number of cancelled and completed nuclear energy sites in the specified time period. This means that if a site were cancelled 1979, for example, its construction could have begun prior to 1979 . 
Table B1. Estimated coefficients from competing risks model, including instrumental variable

\begin{tabular}{|c|c|c|}
\hline Variables & $\begin{array}{c}\text { Stage } 1 \text { Poisson } \\
\text { Model } \\
\text { Model } 1\end{array}$ & $\begin{array}{c}\text { Stage } 2 \text { Competing } \\
\text { Risks Hazard Model } \\
\text { Model } 2\end{array}$ \\
\hline \multirow{2}{*}{ Nearby Nuclear Site Accidents } & $0.394 * * *$ & \\
\hline & $(0.022)$ & \\
\hline \multirow{2}{*}{ Non-anti-nuclear energy claims (instrumented) } & & $-1.740 * * *$ \\
\hline & & $(0.363)$ \\
\hline \multirow{2}{*}{ Number of tactics } & & $0.161 * *$ \\
\hline & & $(0.052)$ \\
\hline \multirow{2}{*}{ Inverse Mills Ratio } & $-0.188 * * *$ & $0.459 * * *$ \\
\hline & $(0.029)$ & $(0.138)$ \\
\hline \multirow{2}{*}{ Unit Power } & $-0.001 * * *$ & $0.004 * * *$ \\
\hline & $(0.000)$ & $(0.001)$ \\
\hline \multirow{2}{*}{ Unit Type $=$ PWR } & -20.754 & $6.081 * * *$ \\
\hline & $(1,772.325)$ & $(0.993)$ \\
\hline \multirow{2}{*}{ Region $=$ Midwest } & -19.433 & -0.269 \\
\hline & $(610.110)$ & $(0.225)$ \\
\hline \multirow{2}{*}{ Region $=$ South } & $-1.638 * * *$ & $0.750 * * *$ \\
\hline & $(0.051)$ & $(0.135)$ \\
\hline \multirow{2}{*}{ Region $=$ West } & $-0.290 * * *$ & $-2.161 * * *$ \\
\hline & $(0.046)$ & $(0.354)$ \\
\hline \multirow{2}{*}{ Number of Nearby Active Nuclear Energy Power Plants } & $-0.077 * * *$ & $-0.213 * * *$ \\
\hline & $(0.007)$ & $(0.022)$ \\
\hline \multirow{2}{*}{ Length of Article } & $0.017 * * *$ & -0.003 \\
\hline & $(0.001)$ & $(0.004)$ \\
\hline \multirow{2}{*}{ Protest near Big City } & $0.305^{* * *}$ & -0.003 \\
\hline & $(0.020)$ & $(0.108)$ \\
\hline \multirow{2}{*}{ Number of Nearby Protests } & $0.002 * * *$ & 0.001 \\
\hline & $(0.000)$ & $(0.001)$ \\
\hline \multirow{2}{*}{ Disruptive tactics } & & -0.066 \\
\hline & & $(0.110)$ \\
\hline \multirow{2}{*}{ Property damage } & & -0.190 \\
\hline & & $(0.255)$ \\
\hline \multirow{2}{*}{ Violence } & & 0.52 \\
\hline & & $(0.302)$ \\
\hline \multirow{2}{*}{ Counterdemonstrators } & & 0.275 \\
\hline & & $(0.331)$ \\
\hline \multirow{2}{*}{ Number of SMOs } & & -0.020 \\
\hline & & $(0.048)$ \\
\hline
\end{tabular}


Duration of Protest

$-0.014$

$-0.019$

Distance between Protest and Nuclear Site (logged)

$0.178 * * *$

$(0.043)$

$\mathrm{N}$

1172 (dyads)

60,721 (dyad-

Log-Likelihood

$-31476$

months)

$-31476$

$-3504$

$* \mathrm{p}<.05, * * \mathrm{p}<.01, * * * \mathrm{p}<.001$ (two-tailed tests)

Note: Event of interest $=$ Nuclear site cancellation, Competing event $=$ Nuclear site completion. We only included one dummy variable for Unit Power Type because only three nuclear sites were of the HTGC power type. Standard errors have been estimated using two-way clustering at the Nuclear Site and Protest Event levels. 